Article

\title{
Cryptic Diversity Hidden within the Leafminer Genus Liriomyza (Diptera: Agromyzidae)
}

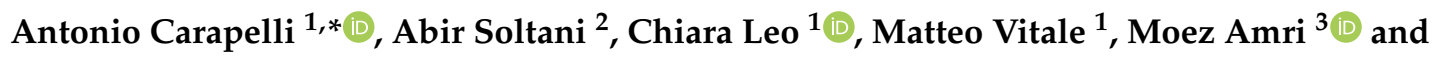 \\ Jouda Mediouni-Ben Jemâa ${ }^{4}$ \\ 1 Department of Life Sciences, University of Siena, Via A. Moro 2, 53100 Siena, Italy; \\ leo6@student.unisi.it (C.L.); matteo.vitale@student.unisi.it (M.V.) \\ 2 Faculté des Sciences de Bizerte, Université de Carthage, 7021 Zarzouna Bizerte, Tunisia; soltani.abir@live.fr \\ 3 Biodiversity and Crop Improvement Program (BCI), International Center for Agricultural Research in the \\ Dry Areas (ICARDA), 10112 Rabat-institutes, Morocco; M.Amri@cgiar.org \\ 4 Laboratoire de Biotechnologie Appliquée à l'Agriculture, INRAT, Université de Carthage, Rue Hedi Karray, \\ 2080 Ariana, Tunisia; j_mediouni@hotmail.fr \\ * Correspondence: antonio.carapelli@unisi.it; Tel.: +39-0577-234410; Fax: +39-0577-234476
}

Received: 17 September 2018; Accepted: 12 November 2018; Published: 15 November 2018

check for updates

\begin{abstract}
Leafminer insects of the genus Liriomyza are small flies whose larvae feed on the internal tissue of some of the most important crop plants for the human diet. Several of these pest species are highly uniform from the morphological point of view, meaning molecular data represents the only reliable taxonomic tool useful to define cryptic boundaries. In this study, both mitochondrial and nuclear molecular markers have been applied to investigate the population genetics of some Tunisian populations of the polyphagous species Liriomyza cicerina, one of the most important pest of chickpea cultivars in the whole Mediterranean region. Molecular data have been collected on larvae isolated from chickpea, faba bean, and lentil leaves, and used for population genetics, phylogenetics, and species delimitation analyses. Results point toward high differentiation levels between specimens collected on the three different legume crops, which, according to the species delimitation methods, are also sufficient to define incipient species differentiation and cryptic species occurrence, apparently tied up with host choice. Genetic data have also been applied for a phylogenetic comparison among Liriomyza species, further confirming their decisive role in the systematic studies of the genus.
\end{abstract}

Keywords: leafminers; cryptic species; species delimitation; population genetics; molecular phylogenetics

\section{Introduction}

Leafminers (Diptera: Agromyzidae) are phytophagous insect pests of great economic interest worldwide and represent one of the largest fly families. Polyphagous species feed on several plantation and horticultural crops, whose leaves are tunneled by the pest larvae. Characteristic serpentine mines damage the leaflets and reduce the yearly yield of many vegetable cultivars. Among the most important leafminer flies, those of the genus Liriomyza (Mik, 1894) are well-known borers of a wide variety of crops. Many of them are host-specific or mine a restricted number of related plants although, among Agromyzidae, the genus adapts to the greatest number of host plants families and has a strong propensity to colonize new hosts [1].

This fly group is believed to be of Neotropic origin and comprises more than 300 species, distributed in most temperate and tropical regions of the planet. Among them, New World taxa, such as Liriomyza huidobrensis, Liriomyza sativae, and Liriomyza trifolii (all polyphagous) are especially troublesome for potatoes, cucurbits, and other horticultural and green house cultivars. One-third 
of the species is naturally found in Europe [2], where major economic damages are attributable to Liriomyza bryoniae, which attacks tomatoes crops. Instead, with respect to the whole Mediterranean region, Liriomyza cicerina is reported to be a severe pest of host plants of the family Fabaceae. Recently, in order to contain their invasive route, some taxa (such as L. huidobrensis, L. sativae, and L. trifolii) have been declared quarantine species in the European and Mediterranean Plant Protection Organization (EPPO) A2 list of pests [3]. Nevertheless, some Liriomyza species have been dislocated from their natural environment and accidentally introduced in new geographical areas, raising major concern among crop growers. To make the whole situation worse, resistance to many conventional insecticidal treatments has already been detected [4].

In general, Liriomyza species are morphologically uniform and therefore, especially difficult to distinguish from the congeneric taxa. Due to their homogeneous structure, neither the shape, nor the size of tunnels, built by the larvae, can be successfully applied for the systematics of the genus. The only diagnostic character, so far applied for Liriomyza species identification, requires dissection of males to inspect genitalia [5]. However, this analysis may be sometimes inconclusive, i.e., in the attempt to distinguish L. huidobrensis and Liriomyza langei [6], or L. trifolii from L. bryoniae and L. sativae [7].

From a systematic point of view, molecular data, either nuclear and mitochondrial, have been applied to investigate the phylogenetic relationships at different taxonomic levels, within Agromyzidae. Combined sets of markers have been used to provide support for the basal dichotomic division of the family in Agromyzinae and Phytomyzinae; but also, to define the phylogenetic relationships among species [1]. However, major efforts have been dedicated to defining species boundaries and, elsewhere to identify cryptic and/or invasive species, in the lack of clear morphological distinction [8-10]. Nowadays, molecular data are the most reliable characters required for Liriomyza species sorting, either using standard and multiplex PCR, and Restriction Fragment Length Polymorphism methods [10-14]. Presently, there are 62 species and 2008 specimens of the genus with barcodes in the Barcode of Life Data System (BOLD); however, only some taxa, such as Liriomyza brassicae, Liriomyza fricki, L. sativae and L. trifolii, are well represented in the Barcode of Life data base ( $>100$ sequences), whereas some other species have no public cox1 sequence at all (e.g., Liriomyza blechi or Liriomyza morio).

Liriomyza cicerina (Rondani 1875) affects several pulse plantations, in most temperate and tropical regions of the World and is a notorious pest of chickpea (Cicer arietinum L.) on which causes serious reduction of yearly crop-production and economic losses. The host plant is damaged either by the adult fly female, that punctures the leaves with its ovipositor to feed on the exudates, or by the larvae mining the mesophyll tissue, when the eggs inserted by the female on the leaf etch. Agricultural damages on chickpea production is particularly alarming for some Mediterranean farmlands. Cicer arietinum is an important source of human food and the World's third most cultivated pulse crop. In the Mediterranean region, several countries (especially those of the North-African side of the sea basin) suffer the consequences of the pest activities on cultivars, with estimated loss of seed production up to $30 \%$, every year. Liriomyza cicerina is native to the Mediterranean area and was formerly a parasite of Ononis species that switched host to chickpea, once this legume crop was introduced from Asia to Southern Europe [2]. Despite, their good-adaptation to arid and semi-arid environments, L. cicerina populations density increases under irrigated conditions. The fly has a polyvoltine reproductive life-cycle which is influenced by average temperature and latitudinal gradient, emerging during springtime (April) until mid-August and overwintering as pupae. Date of emergence may be earlier in warmer climate regions, with a complete life-cycle of 20-30 days and up to three overlapping generations after the first.

Molecular knowledge on L. cicerina is very limited with only one sequence available in both GenBank and BOLD. However, specimens of the genus have been intercepted in different hosts of Fabaceae (i.e., chickpea, lentil and faba bean) and are usually treated as a single species [15]. Therefore, either: (1) L. cicerina is highly polyphagous and adapts well to a vast number of hosts; or (2) more than one species is hidden within the same taxonomic name, each one with its preferred host. 
In this study, we have analyzed, to our knowledge for the first time, the population genetics of several L. cicerina samples, collected from localities in Tunisia, where chickpea, lentil and faba bean cultivars are present, using the popular cytochrome $c$ oxidase subunit I marker (cox1). This survey represents the first attempt to describe the genetic variability of the species in North-African Countries, and to provide a list of sequences useful for its barcode identification. Analyzed specimens were collected on different host plants (chickpea, faba bean and lentil) to establish if host-specific genetic groups form monophyletic clusters within the phylogenetic tree of the Liriomyza species. Moreover, distance-based, maximum likelihood and Bayesian species delimitation methods were applied to evaluate their taxonomic status and to assess the presence of unidentified species complexes. The multispecies coalescent approaches, although relying on single-locus, and frequently lessened as inaccurate or more adapt to distinguish the population structure of a species [16], still remain a good way to provide hypotheses on inter- and intraspecific boundaries in the presence of cryptic species [17]. Therefore, a combined set of nuclear (28S ribosomal DNA (rDNA) encoding for the large ribosomal subunit; and $C A D$, encoding for the carbamoyl-phosphate synthetase 2) and mitochondrial (cox1) markers have been applied in this study for: (1) single- (i.e., cox1, CAD and 28S, individually) and multi-locus (i.e., concatenate of the three markers) species delimitation; (2) a phylogenetic comparison among congeneric species aimed at unveiling the deeper branching of Liriomyza lineages. Resulted genetic screening has subsequently prompted an ongoing preliminary morphological study of specimens belonging to alternative clusters in order to evaluate the occurrence of cryptic species and their relationships with the host plants (data not shown).

\section{Materials and Methods}

\subsection{Sampling Collection, DNA Extraction and Sequencing}

Larvae of L. cicerina were collected, during 2016 and 2017 spring, on chickpea, faba bean and lentil from ten different localities in the North of Tunisia where these legume crops are mainly cultivated (Figure 1; Table 1). The specimens were morphologically identified by researchers from INRAT (Institut National de Recherche Agronomique de Tunis), and were preserved in alcohol for further morphological and molecular analyses. Most of samples were isolated from chickpea plants, whereas only five from lentil and eight from faba bean (Table 1).

Table 1. List of the Tunisian sampling sites, with respective labels and geographic coordinates; Béja, Amdoun, Hamrounia and Hamem Sayela are sites of the Béja Region; for each area the host plant, the number of specimens analyzed are listed, as well as the haplotypes identified in this study.

\begin{tabular}{cccccc}
\hline Collection site & Label & Coordinates & Host Plant & n & cox1 Haplotypes \\
\hline Béja & & & Cicer arietinum & 10 & $\mathrm{~A}(9), \mathrm{B}(1) \mathrm{C}(1), \mathrm{O}(1)$ \\
& $\mathrm{BEJ}$ & $36^{\circ} 43^{\prime} \mathrm{N} ; 9^{\circ} 10^{\prime} \mathrm{E}$ & $\begin{array}{c}\text { Lens culinaris } \\
\text { Vicia faba }\end{array}$ & 5 & $\mathrm{~A}(1), \mathrm{L}(1), \mathrm{M}(1), \mathrm{N}(1), \mathrm{P}(1), \mathrm{Q}(1), \mathrm{R}(1), \mathrm{S}(3), \mathrm{T}(1), \mathrm{U}(1)$ \\
Amdoun & $\mathrm{AMD}$ & $36^{\circ} 46^{\prime} \mathrm{N} ; 9^{\circ} 05^{\prime} \mathrm{E}$ & Cicer arietinum & 13 & $\mathrm{~A}(12), \mathrm{F}(1)$ \\
Hamrounia & $\mathrm{HAM}$ & $36^{\circ} 72^{\prime} \mathrm{N} ; 9^{\circ} 11^{\prime} \mathrm{E}$ & Cicer arietinum & 10 & $\mathrm{~A}(10)$ \\
Hamem Sayela & $\mathrm{HSA}$ & $36^{\circ} 39^{\prime} \mathrm{N} ; 9^{\circ} 8^{\prime} \mathrm{E}$ & Cicer arietinum & 10 & $\mathrm{~A}(8), \mathrm{G}(1), \mathrm{H}(1)$ \\
Le Kef & $\mathrm{KEF}$ & $36^{\circ} 11^{\prime} \mathrm{N} ; 8^{\circ} 42^{\prime} \mathrm{E}$ & Cicer arietinum & 12 & $\mathrm{~A}(8), \mathrm{C}(1)$ \\
Mornag & $\mathrm{MOR}$ & $36^{\circ} 41^{\prime} \mathrm{N} ; 10^{\circ} 1^{\prime} \mathrm{E}$ & Cicer arietinum & 10 & $\mathrm{~A}(8), \mathrm{D}(1), \mathrm{E}(1)$ \\
Oued Meliz & $\mathrm{JEN}$ & $36^{\circ} 28^{\prime} \mathrm{N} ; 8^{\circ} 33^{\prime} \mathrm{E}$ & Cicer arietinum & 10 & $\mathrm{~A}(9), \mathrm{C}(1)$ \\
Mateur & $\mathrm{MAT}$ & $37^{\circ} 02^{\prime} \mathrm{N} ; 9^{\circ} 39^{\prime} \mathrm{E}$ & Cicer arietinum & 10 & $\mathrm{~A}(10)$ \\
Bizerte & $\mathrm{BIZ}$ & $37^{\circ} 16^{\prime} \mathrm{N} ; 9^{\circ} 52^{\prime} \mathrm{E}$ & Cicer arietinum & 10 & $\mathrm{~A}(10)$ \\
Menzel Bourguiba & $\mathrm{MBO}$ & $37^{\circ} 9^{\prime} \mathrm{N} ; 9^{\circ} 47^{\prime} \mathrm{E}$ & Cicer arietinum & 10 & $\mathrm{~A}(7), \mathrm{I}(1), \mathrm{J}(1), \mathrm{K}(1)$ \\
\hline
\end{tabular}



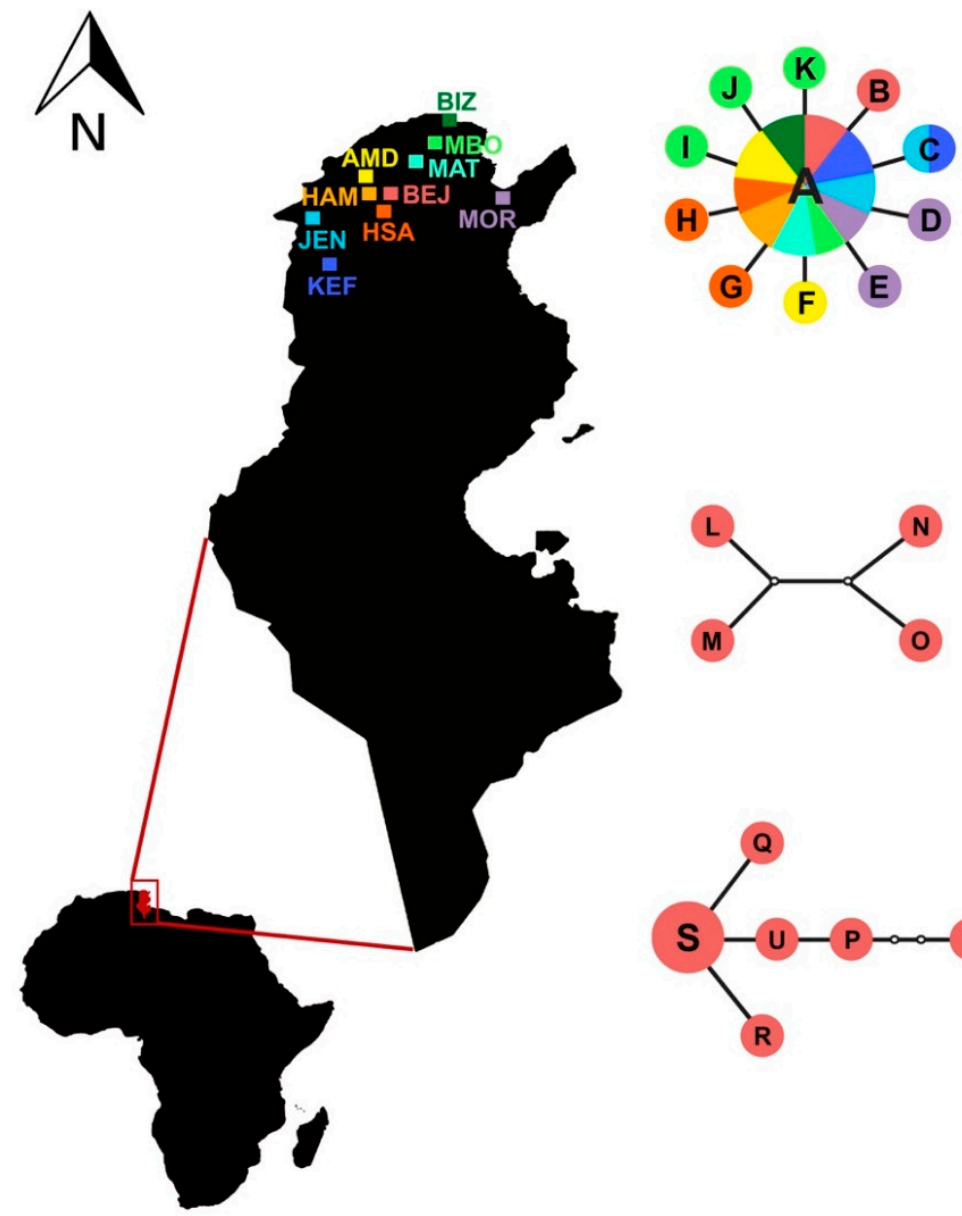

1.

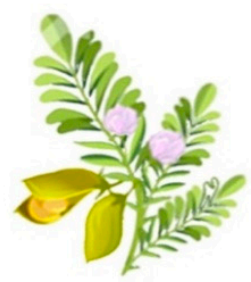

2.
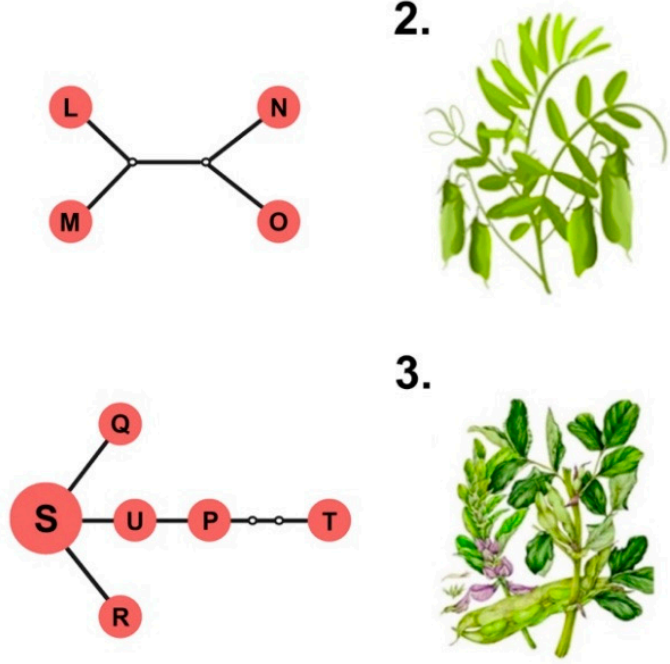

Figure 1. Map of Tunisia, with sampling sites represented with a three-letter code (see Table 1). In the middle, the three haplotype networks identified in the population genetics analysis of Liriomyza cicerina, corresponding to specimens collected on: (1) Cicer arietinum; (2) Lens culinaris; (3) Vicia faba, with the only exception of one specimen from lentils which share the haplotype A with those sampled on chickpea. The haplotype (circle) size is proportional to its frequency; black lines represent one nucleotide substitution, whereas white circles the missing haplotype. Plants images downloaded from [18].

The whole genomic DNA was extracted by means of the Wizard ${ }^{\circledR}$ SV genomic DNA Purification System (Promega, Madison, WI, USA) and used to amplify the mitochondrial barcode gene cox1. The fragment was selected using the primers LCO (5'-GGTCAACAAATCATAAAGATATTGG- $\left.{ }^{\prime}\right)$, and HCO (5'-TAAACTTCAGGGTGACCAAAAAATCA-3') [19]. The total reaction volume of $25 \mu \mathrm{L}$ contained $2.5 \mu \mathrm{L}$ of genomic DNA, $0.5 \mathrm{mM}$ of each primer, $0.2 \mathrm{mM}$ of each deoxynucleotides (dNTPs, $10 \mathrm{mM}$ ), $2.5 \mathrm{mM}$ of $\mathrm{MgCl}_{2}, 5 \mu \mathrm{L}$ of Green GoTaq Flexi buffer and $0.625 \mathrm{u}$ of GoTaq Flexi DNA Polymerase (Promega). The amplifications were performed in a GeneAmp ${ }^{\circledR}$ PCR System 2700 (Applied Biosystems, Foster City, CA, USA) thermal cycler. The initial denaturation step was set at $95^{\circ} \mathrm{C}$ for $5 \mathrm{~min}$, followed by: 35 cycles at $94{ }^{\circ} \mathrm{C}$ for $1 \mathrm{~min}, 50^{\circ} \mathrm{C}$ for $1 \mathrm{~min}$ and $72{ }^{\circ} \mathrm{C}$ for $90 \mathrm{~s}$, and a final extension step at $72{ }^{\circ} \mathrm{C}$ for $7 \mathrm{~min}$.

In order to amplify both $C A D$ and $28 S$ genes, the sequences of Liriomyza spp. available on Genbank were downloaded and aligned using the online tool Clustal Omega (https:// www.ebi.ac.uk/Tools/msa/clustalo/) (accession numbers in Table S1 in the Supplementary Materials); primers were then identified in conserved regions. The $C A D$ gene was selected with the oligo pair: Lir-CAD-53F (5'-ATGAGAAAGATGAATATGGYATGCC-3') and Lir-CAD-689R (5'-TGRCCRCGATTACCAAATTTCAT-3'); whereas the large ribosomal subunit was amplified with: Lir-28S-31F (5'-TAGTAGTGGCGAGCGAAAAGA-3') and Lir-28S-1366R (5'-GTATCAGTATGAGTT 
GCTAATTTGGG-3'). The PCRs were performed as aforementioned, varying only the elongation time for $28 S$ gene from $90 \mathrm{~s}$ to $2 \mathrm{~min}$. The PCR products were then purified using the kit Wizard ${ }^{\circledR} \mathrm{SV}$ Gel and PCR Clean-up (Promega), and sequenced on both strands with a DNA Analyzer ABI 3730, at the core facility of the Biofab Research Lab (Rome, Italy). The sequences were assembled and manually corrected using Sequencher 4.4.2 (Gene Codes Corporation, Ann Arbor, MI, USA) and deposited in GenBank under accession numbers: MH878802-MH878822 for cox1, MH878823-MH878828 for CAD and MH878829-MH878830 for 28S rDNA.

\subsection{Assembling the Data Sets}

About ten specimens from each of the ten sampling sites of this study were included in the single-locus (cox1) analyses, corresponding to 115 sequences, collected on C. arietinum, Lens culinaris and Vicia faba. Because of the uniform morphology typical of the agromyzid species, a similarity search against both the Nucleotide Basic Local Alignment Search Tool (BLASTn) and BOLD databases was performed. The initial cox 1 data set was then assembled and aligned using the online tool Clustal Omega. The alignment was manually corrected using the software Mesquite 3.51 [20] and it resulted in a 658 bp matrix, with no indels.

Moreover, about 20 specimens from Béja region were screened also for the two nuclear markers chosen for our analyses. Six different haplotypes of $C A D$ gene were identified among L. cicerina specimens sampled on C. arietinum, L. culinaris and $V$. faba (i.e., two for each of the pest-host complex analyzed); whereas, only two different $28 S$ rDNA variants were obtained: one corresponding to specimens sampled on both chickpea and lentil, the other specific for specimens isolated from faba bean.

Thereafter, three single-locus and one multi-locus data sets were assembled. The cox 1 sequences obtained in the present study were aligned with those of 24 species belonging to the genus Liriomyza and to three agromyzid species used as outgroups: Calycomyza majuscula, Calycomyza malvae and Cerodontha fasciata (GenBank accession numbers and BOLD codes in Table S2 in the Supplementary Materials). The $C A D$ and $28 S$ sequences of $L$. cicerina were individually aligned with those obtained by Scheffer et al. [1] resulting into two matrices of $591 \mathrm{bp}$ and $1011 \mathrm{bp}$ in length, respectively. These latter data sets were restricted only to the Liriomyza spp. for which the two nuclear markers were available on Genbank, and to the same outgroup taxa as before (see Table S1 in the Supplementary Materials). Finally, to further investigate the evolutionary relationships among L. cicerina specimens and to provide a phylogenetic reconstruction among the species of the genus, a concatenate of cox1, CAD and $28 \mathrm{~S}$ genes (i.e., multi-locus data set) was assembled.

In order to avoid artefacts during the phylogenetic analyses, the $28 S$ rDNA alignment was deprived of the hyper-variable regions using the online tool Gblocks server [21]. The $87 \%$ of the initial $28 S$ rDNA data set was conserved and concatenated to the cox 1 and $C A D$ alignments through the software Mesquite 3.51 [20].

\subsection{Genetic Variability}

The cox 1 single-locus data set was used for the network clade analysis, performed by means of the software TCS 1.21 [22] using the default setting of $95 \%$ connection limit. The haplotype frequencies were obtained through the online tool DNA-Collapser [23]. The proportion of nucleotide changes between the haplotypes ( $p$-distance) identified among L. cicerina specimens and against all the different outgroups was calculated using the package APE developed under the R environment [24]. The comparison between L. cicerina and the other species was necessary to both define the genetic variability threshold at an inter- and intra-specific level and to further avoid misidentification of the larvae during the analyses.

\subsection{Phylogenetic Analyses}

The cox 1 and $C A D$ single-locus data sets, assembled as described before, were partitioned into three different charsets (1st, $2 \mathrm{nd}$, and 3rd codon positions), whereas the $28 \mathrm{~S}$ was considered as a single 
partition. The software PartitionFinder 2 [25] was applied to find the evolutionary models that best fit our data sets. In order to infer a rooted topology to investigate both the putative presence of host-specific clusters within L. cicerina and its evolutionary relationships with the other congeneric species, the data sets were individually tested with both Maximum-likelihood (ML) and Bayesian inference (BI) methods, as implemented in RaxML 8.2.9 [26] and MrBayes 3.2 [27], respectively. The Maximum-likelihood analysis was executed using RAxML, run on the CIPRES Science Gateway V. 3.3 [28] under the GTR + $\Gamma$ model with eight categories of discrete gamma distribution. The procedure included 100 independent runs of the ML analysis and 1000 replicates of the multi-parametric bootstrap. The program MrBayes 3.2 [27] was then run applying four chains for $10^{6}$ generations, with a sampling frequency of one tree every 1000 iterations, and with the $25 \%$ of the tree topologies discarded (burn-in step).

The multi-locus data set (i.e., a concatenate of $\operatorname{cox1} 1, C A D$ and 28S) was further divided into seven different partitions: 1st, 2nd, 3rd codon positions for cox1 gene; 1st, 2nd, 3rd codon positions for CAD gene; and, the $28 S$ rDNA region. The software PartitionFinder 2 [25] was again applied to identify the best evolutionary models and both ML and BI were run as described before.

\subsection{Species Delimitation Analyses}

The 109 barcode sequences, included in the cox 1 data set, were downloaded from BOLD System (Table S2 in Supplementary Materials). Given the pronounced morphological homogeneity, typical of agromyzid species, the classification of those specimens was reassessed through molecular species delimitation methods based on pairwise distances (ABGD [29], Species Identifier 1.8 [30] and TCS [22]), as well as on maximum likelihood (GMYC) and Bayesian (bPTP and BPP) optimization criteria.

The online tool Automatic Barcode Gap Discovery (ABGD, http:/ / wwwabi.snv.jussieu.fr/public/ abgd/abgdweb.html) was applied to detect the barcode gap within the distribution of pairwise distances obtained from a sequence alignment [29]. The analysis was performed using the Kimura two-parameter (K2P) model, defining the priors minimum and maximum intra-specific divergence as 0.001 and 0.05 , respectively, and a gap width of 1 . The species delimitation was also tested with the software Species Identifier [30], that split the sequences in clusters (i.e., putative species) based on the maximum intra-specific and the minimum inter-specific divergence identified from the barcode gene data set.

The Poisson Tree Process (PTP) was applied in order to define species boundaries based on a phylogenetic method [31]. The analyses were carried out on the web server bPTP (http:/ / species.h-its. org/ptp/), using either the MrBayes and the RAxML topologies as input rooted tree. Each analysis was run for 500,000 MCMC generations with a burn-in value of 0.25 and performed both including and excluding the outgroup species.

The ultrametric tree, was obtained by means of the software BEAST 2.4.8 [32]. The GTR $+\Gamma+\mathrm{I}$ model was applied to each partition (1st, 2nd and 3rd codon positions) and base frequencies estimated during the analysis. A strict molecular clock was applied, defining the clock.rate based on the average mutation rate per million year identified in Brower [33], with a coalescent model of constant population size as tree prior. Two independent MCMC runs were performed, constituted of $10^{6}$ generations with parameters sampled every 1000 iterations and a burn-in of $25 \%$. The two runs were combined through the BEAST package LogCombiner 2.4.8 [32]. The convergence of MCMC chains was assessed with Tracer v 1.7 [34] and the consensus tree visualized through the software FigTree v1.4.3 [35].

The ultrametric topology was then applied for the single-threshold GMYC (Generalized Mixed Yule Coalescent method [36]) analysis as well. This latter was conducted in R 3.3.2 (R Core Team 2016 [37]) with the use of the splits package [38].

The Bayesian Phylogenetics \& Phylogeography (BPP) program was used to carry out either the single-locus (i.e., cox1, CAD and $28 S$ data sets, singularly analyzed) and the multi-locus (i.e., the concatenate of the three molecular markers) species delimitation analyses under the multispecies coalescent model [39]. In particular, the joint species delimitation and species-tree inference was performed (i.e., speciesdelimitation $=1$, speciestree $=1$; A11, [39]). The algorithm 0 and the default 
settings for fine-tuning parameters were used $(\varepsilon=5)$, as well as the species model prior 1 (i.e., uniform probability for rooted tree). Since no empirical data were available for the studied species to define appropriate priors distribution of the parameters $\theta$ (ancestral population size) and $\tau$ (root age), the species delimitation analyses were run with the following combination of gamma distributions: (1)

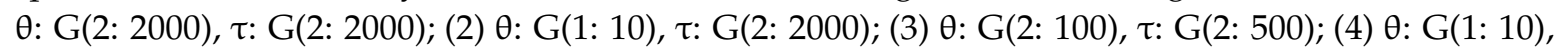
$\tau: G(1: 10)$. The analyses were run for 100,000 MCMC generations, with a sample frequency of 50 and a burn-in of 1000 generations; each analysis was run twice in order to confirm the consistency of the results.

Finally, the software TCS v1.21 [22] was applied again to the cox1 data set of those Liriomyza species that have been split into different clusters by the analyses, as a further evidence for the presence of putative cryptic species.

\section{Results}

\subsection{Haplotypes and Population Genetics Analyses}

A total of 115 individual sequences were obtained from specimens sampled in 10 Tunisian sites and from three different host plants (chickpea, lentil and faba bean, Table 1). Among the 21 haplotypes observed in the $\operatorname{cox} 1$ data set, $\mathrm{A}$ is the most frequent, and shared by all populations with the exception of those specimens isolated from $V$. faba plants. In addition, most of the sampling areas shows a unique set of haplotypes, except for KEF and JEN, which share both A and C variants.

The estimated network shows three well-distinct phylogroups, corresponding to specimens collected on chickpea, lentil and faba bean, respectively (Figure 1), displaying signs of divergent selection among host plants in these leafminers. Haplotypes from specimens collected on C. arietinum host are arranged in a star-like network, with the haplotype A being the ancestral and most frequent variant observed, from which the haplotypes B-K differ for only one nucleotide substitution (Figure 1). Although one of the specimens isolated from L. culinaris has one haplotype (A) clustered with the chickpea group, all the other haplotypes identified for the lentil subset form a separated phylogroup of sequences (Figure 1) that differs for two or three nucleotide substitutions each other and for 27 to 32 nucleotide substitutions from chickpea haplotypes. Finally, the third subset is constituted only by the haplotypes detected among specimens isolated from $V$. faba host, again grouped within an exclusive haplotype sub-network (Figure 1). Within this latter cluster, the haplotype $S$ results the ancestral and most frequent, from which all the other variants (P-R and T-U) are derived and differ for one to five substitutions (Figure 1).

Within host-specific variability of specimens collected on $V$. faba ranges from one to seven nucleotide substitutions, whereas comparisons of these latter haplotypes with those obtained from C. arietinum and L. culinaris are from 88 to 93 , and from 83 to 90, respectively. The average pairwise distance values, calculated within and between the Liriomyza species and the three outgroup taxa (C. majuscula, C. malvae and C. fasciata) included in the present study, range from $0.10 \%$ (among C. fasciata haplotypes) to $17.53 \%$ (Liriomyza ptarmicae vs. Liriomyza flaveola) (Table 2). Within species, the average genetic distances vary from $0.10 \%$ (again C. fasciata haplotypes) to $1.93 \%$ (observed comparing L. flaveola haplotypes) (Table 2). Genetic variability among the two cryptospecies L. huidobrensis and L. langei is $5.76 \%$. Liriomyza strigata and the closely related L. bryoniae and L. huidobrensis show $p$-distance values of $6.54 \%$ and $7.30 \%$, respectively. The comparison among specimens of L. cicerina sampled on chickpea and lentil shows a value of about $4.60 \%$, whereas the average genetic distances of these latter against $L$. cicerina isolated from faba bean is $13.87 \%$ and $13.13 \%$, respectively (Table 2). It is not possible to establish a cut-off value to delimit intra- from inter-specific distances (barcoding gap), due to overlap of distances observed within and between species comparisons (see diagram on Figure 1). 
Table 2. Percentage of average pairwise distance matrix; in yellow are highlighted values of intra-specific divergence; in red unexpected values of inter-specific divergence within the same species complex.

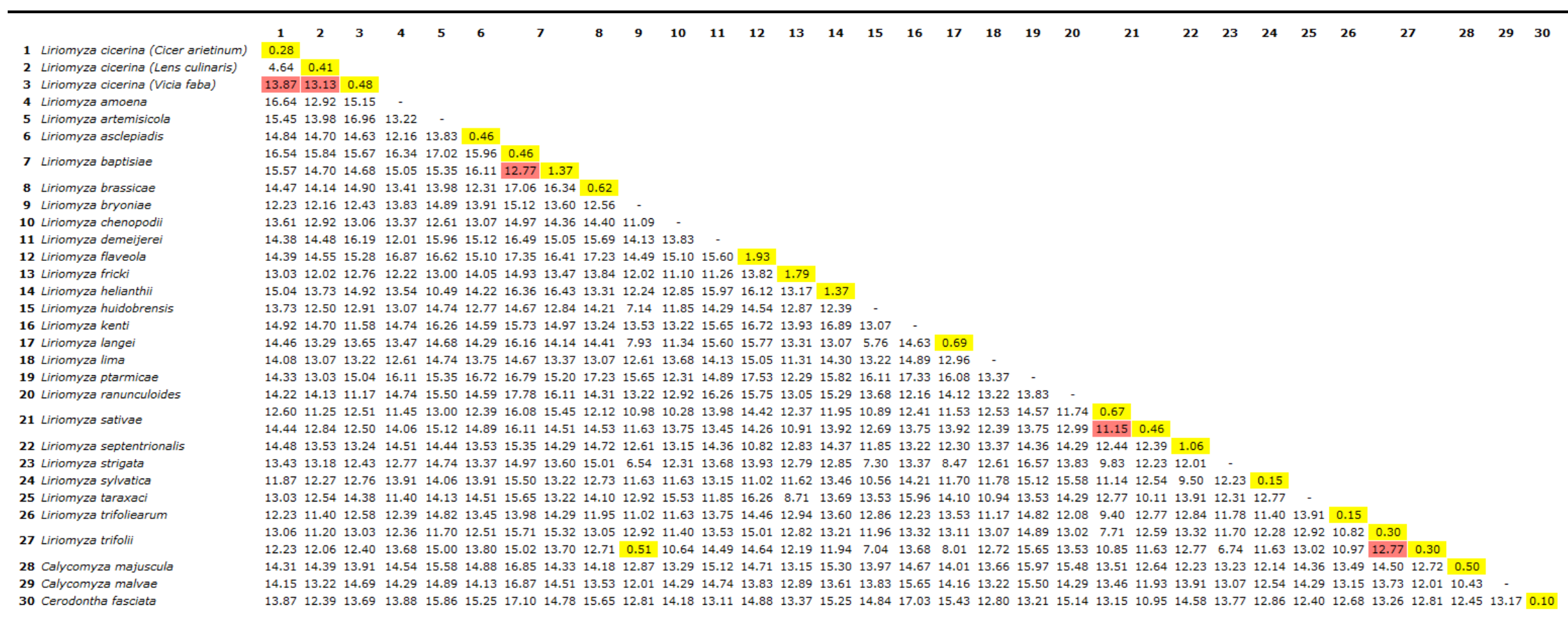




\subsection{Phylogeny of the Genus Liriomyza}

The evolutionary models identified with the software PartitionFinder [25] were: GTR $+\Gamma$ for both 1st and 3rd codon positions and GTR $+\mathrm{I}+\Gamma$ for the 2nd positions of the cox1 single-locus data set; GTR $+\Gamma$ for 1st codon position and GTR $+\mathrm{I}+\Gamma$ for 2 nd and 3rd CAD codon positions, as well as for the entire 28S.

Instead, for the multi-locus data set the following models were selected: GTR $+\Gamma$, for $\operatorname{cox} 1$ 3rd positions and for CAD 1st and 3rd positions; GTR+I for cox 1 2nd positions; GTR $+\mathrm{I}+\Gamma$ for the $28 \mathrm{~S}$ rDNA portion, the $\operatorname{cox} 1$ 1st positions and for $C A D$ 2nd positions. The topologies obtained with both $\mathrm{ML}$ and $\mathrm{BI}$ applied to the three single-locus data sets are fairly congruent, showing higher support for several nodes (Figures 2 and 3).

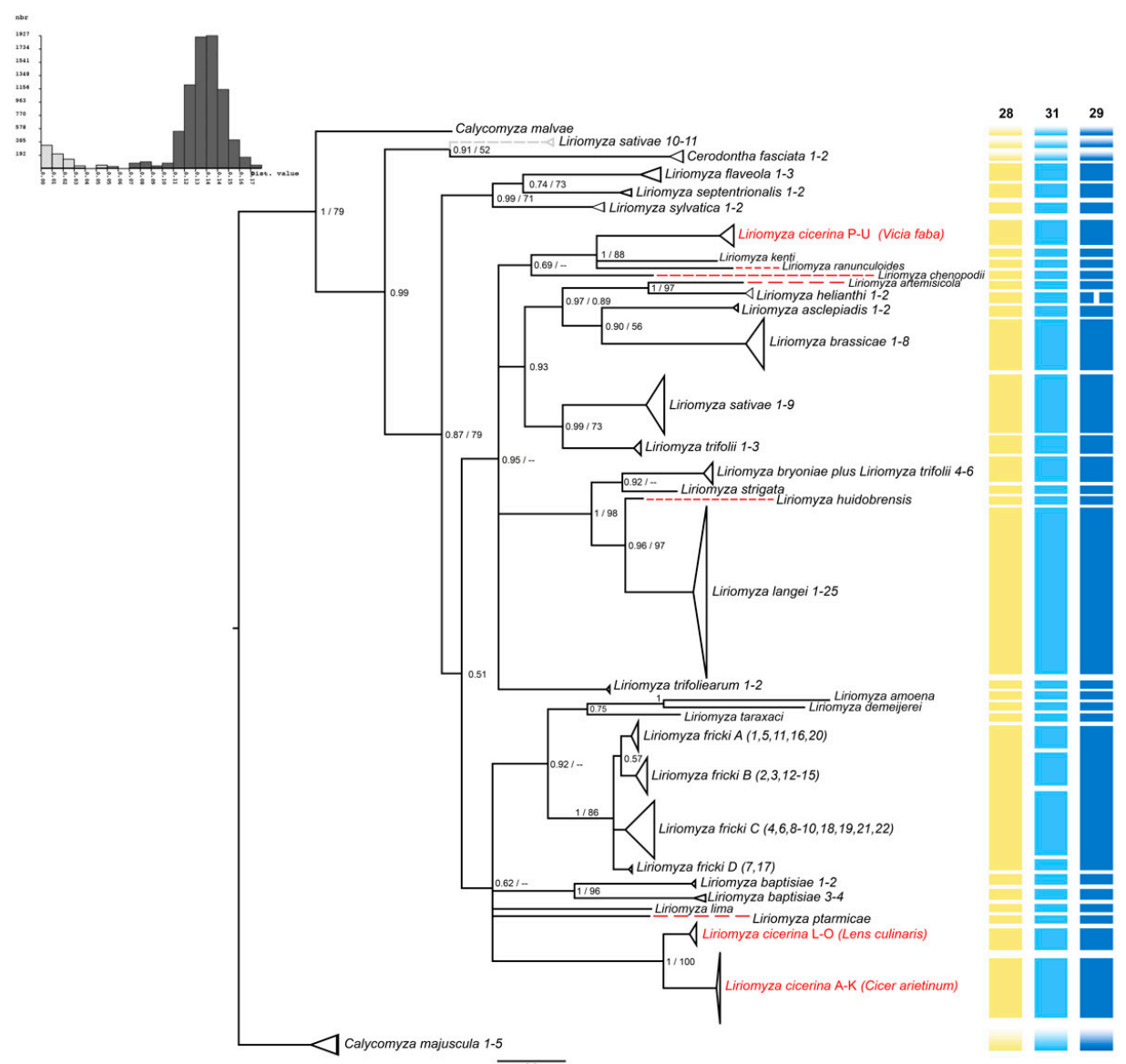

Figure 2. The phylogenetic tree obtained through Bayesian inference (BI), applying the cytochrome $c$ oxidase subunit one (cox1) data set. At each node of the tree are shown the BI posterior probabilities, as well as the Maximum-Likelihood (ML) bootstrap values; dashes depict when the node is not represented in both BI and ML topologies. In red, the three L. cicerina clusters. Top left, the barcode gap diagram. On the right, a summary of the species delimitation methods performed on the single-locus data set. Shaded boxes indicate the outgroup species. Yellow bars show the 28 clusters detected by the programs: Automatic Barcode Gap Discovery (ABGD), Species Identifier, PTP (Poisson Tree Process) (applying BI topology and including the outgroup species) and Bayesian Phylogenetics \& Phylogeography (BPP). Light blue bars display the 31 species identified by the Generalized Mixed Yule Coalescent (GMYC) model and PTP (run with BI topology and excluding the outgroup species) method. Blue bars indicate the results of PTP analyses performed with ML topology, either including and excluding the outgroup species. Top right, the total number of Liriomyza spp. detected by each species delimitation method applied. 


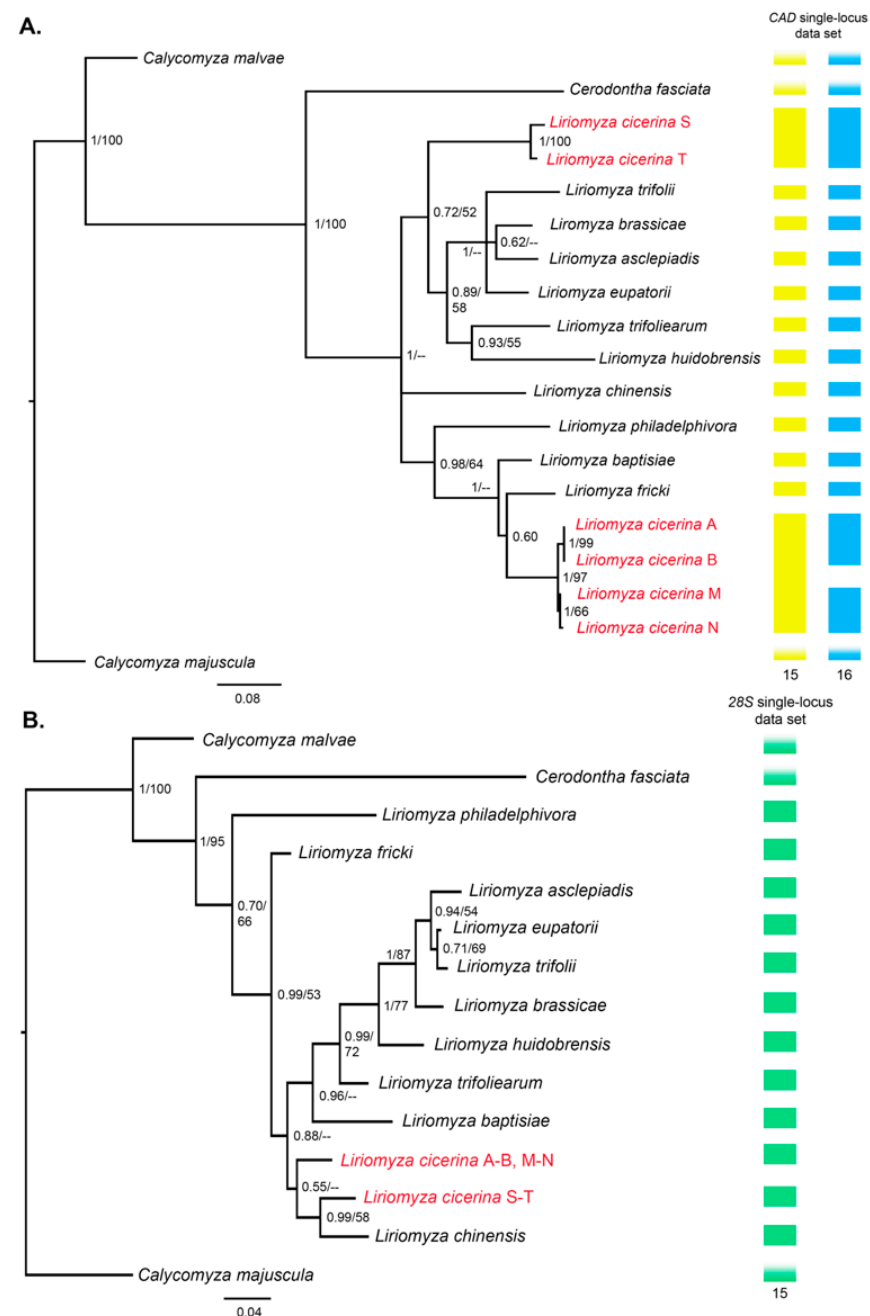

Figure 3. The phylogenetic trees obtained through BI, applying the single $C A D(\mathbf{A})$ and $28 S(\mathbf{B})$ data sets. At each node of the tree, the BI posterior probabilities are shown, as well as the Maximum-likelihood (ML) bootstrap values; dashes depict when the node is not represented in both BI and ML topologies or when the bootstrap value was $<50$. On the right side of each tree, the results of the BPP species delimitation analyses are summarized. Yellow bars show the species clusters identified, applying the $C A D$ gene, when the gamma distributions were set as: $\theta: G(1: 10), \tau: G(1: 10)$ and $\theta: G(2: 100), \tau: G(2$ : $500)$. Blue bars display the species detected with the same data set and when BPP was run with $\theta: G(2$ : 2000), $\tau: G(2: 2000)$ and $\theta: G(1: 10), \tau: G(2: 2000)$. Green bars summarize the BPP outputs when the analyses were performed using the $28 S$ single-locus data set. Underside each series of bars, the total number of the species clusters detected is shown. Shaded boxes indicate the outgroup species.

When the cox 1 data set is applied to the phylogeny of the Liriomyza genus, most species are retrieved as monophyletic, some of them without a defined, closer, relationship with other taxa (e.g., Liriomyza baptisiae and Liriomyza trifoliearum). In both BI and ML trees, the genus Liriomyza results to be paraphyletic, with two haplotypes of L. sativae from South Korea (10 and 11: KC136117 and KC136118, respectively) clustered with the outgroup C. fasciata (Figure 2, posterior probability (PP) $=0.91)$. L . sativae (10-11) and C. fasciata (1-2) attract reciprocally at basal position of all ingroups. Removal of C. fasciata from the phylogenetic analysis (MrBayes and Beast analyses) does not result to monophyetic L. sativae (data not shown). We focus our description on the most important and notorious leafminer species, usually considered also for quarantine legislation in various countries: L. bryoniae, L. huidobrensis, L. sativae and L. trifolii. Although most of the Liriomyza species included in this study turn out to be monophyletic, some haplotypes of L. trifolii from South Korea (KC136095, KC136096 
and the identical: KC136097-KC136098), referred to as L. trifolii 4-6, cluster with L. bryoniae, instead of L. trifolii 1-3 (EU219614, JN570506 and KR476574, respectively) from China and US (this latter cluster, sister to L. sativae 1-9; Figure 2). The lineage L. trifolii 4-6 and L. bryoniae, plus L. strigata, is sister to the group formed by the two morpho-cryptic species L. huidobrensis and L. langei. The monophyletic lineage inclusive of the L. brassicae and Liriomyza asclepiadis specimens has a strict phylogenetic relationship with the assemblage (Liriomyza artemiscola, Liriomyza helianthi). All these latter species form with L. sativae plus L. trifolii a monophyletic group. Other proposed phylogenetic relationships establish for: (Liriomyza sylvatica, (L. flaveola, Liriomyza septentrionalis)) and (L. frickii, (Liriomyza taraxaci, (Liriomyza amoena, Liriomyza demeijeri))).

The cox 1 haplotypes detected among specimens of $L$. cicerina isolated from faba bean host (P-U) cluster with Liriomyza kenti and Liriomyza ranunculoides (Figure 2), rather than being sister group of the haplotypes (A-O) obtained from larvae grown on both chickpea and lentil. The same result is observed when the $C A D$ tree is inferred with either BI and ML optimization criteria (Figure 3A). The two haplotypes (S-T) of L. cicerina sampled on faba bean leaves are sister group of ((L. huidobrensis, L. trifoliearum), (L. trifolii, Liriomyza eupatorii, (L. brassicae, L. asclepiadis))). Again, they cluster neither with the haplotypes detected for L. cicerina from C. arietinum (A-B) nor with those of specimens sampled on L. culinaris (M-N, Figure 3A). A more recent common ancestor, among L. cicerina samples from different host plants, is instead inferred when the $28 \mathrm{~S}$ single-locus is applied for the analyses. Either the BI and the ML would suggest that the shared haplotype, detected between specimens from chickpea and lentil, may be the sister group of L. cicerina from faba bean and of Liriomyza chinensis (Figure 3B). However, both topologies show low support to that node (bootstrap value $<50 ; \mathrm{PP}=0.50$ ).

Deeper relationships, along the cox1 topologies, and the shallow ones, obtained when $C A D$ and $28 S$ data sets are applied for Liriomyza phylogeny, are not shown with sufficient statistical support. Conversely, the phylogenetic trees (BI and ML), obtained using the concatenated data set of cox1, $C A D$ and $28 S$ rDNA genes, show highly supported nodes for most of the branches with the genus Liriomyza being monophyletic (for convenience, along the text we identify the L. cicerina specimens with the haplotype name, previously used for the population genetics study). In addition, both analyses confirmed the host-specific split of L. cicerina haplotypes into two different clades. Faba bean specimens (S-T) are the sister group of a sub-clade that includes: (((L. asclepiadis, L. brassicae), L. eupatorii), L. trifolii), (L. huidobrensis, L. trifoliearum) (Figure 4). Instead, specimens isolated from both chickpea and lentil (A, B, M, N) cluster together with L. fricki and L. baptisiae being their basal group (Figure 4). Applying the concatenated data set, the two topologies, inferred with the two different optimization criteria (BI and ML), are coherent and generally fully supported. The only exception is the position of L. chinensis and Liriomyza philadelphivora (shown in gray in Figure 4) which, in turn, are sister group and basal to all the other Liriomyza spp. included in the present analysis (BI tree) (Figure 4), or (according to the ML topology) are independent basal lineages of the two major branches of the tree clustering with the upper branch (L. chinensis), or with the lower one (L. philadelphivora) on Figure 4.

\subsection{Molecular Species Delimitation}

The cox 1 data set analyzed in the present study was assembled with the sequences of 24 Liriomyza species downloaded from public data bases, and those of L. cicerina (obtained in our lab), plus three outgroups (Table S2 in the Supplementary Materials). Applied methods of species delimitation, using the mitochondrial single-locus data set, have resulted in the identification of a larger number (from 28 to 31) of putative Liriomyza species (Figure 2). Performed molecular analyses detect some probable misidentification of taxa. In this respect, as already observed in the phylogenetic tree, three L. trifolii haplotypes (identified with numbers 4-6) are joined with L. bryoniae within a single taxon (all methods, Figure 2); whereas others (1-3) are sister group to L. sativae. Given the apparent difficulties in sorting L. trifolii from L. bryoniae, we believe the former (represented by haplotypes 4-6) was misidentified and probably belong to the latter species. Similarly, two haplotypes of L. sativae (numbers 10 and 11) cluster in a different position of the phylogenetic tree, with respect to the remaining conspecific taxa (that are 
sister to L. trifolii) (Figure 2) and, according to molecular species-delimitation, are apparently related to the outgroup C. fasciata. This would also suggest a misidentification at the genus level and therefore we believe there was another (mislabeling?) error during their taxonomic identification. Whether L. sativae haplotypes (10-11) belong or not to a taxon of Liriomyza, or to a different (Cerodontha?) genus, is difficult to establish. Therefore, we have excluded these two sequences from the count list of the Liriomyza species. The ABGD, Species Identifier, TCS, PTP "MrBayes 1" (using a Bayesian input tree and a data set inclusive of three outgroups) and BPP (with alternative parameter settings) methods all detected the same 28 taxa instead of the 25 usually accepted for taxonomy (yellow bars in Figure 2). The "extra" three are retrieved thanks to the separation of the four haplotypes of L. baptisiae, which were split into two putative species $(1+2$ and $3+4)$; and by L. cicerina, that all species delimitation methods, applied to the cox 1 marker, were concordant to separate into three clusters, according to their preferred host plant: C. arietinum, L. culinaris and V. faba groups (Figure 2).
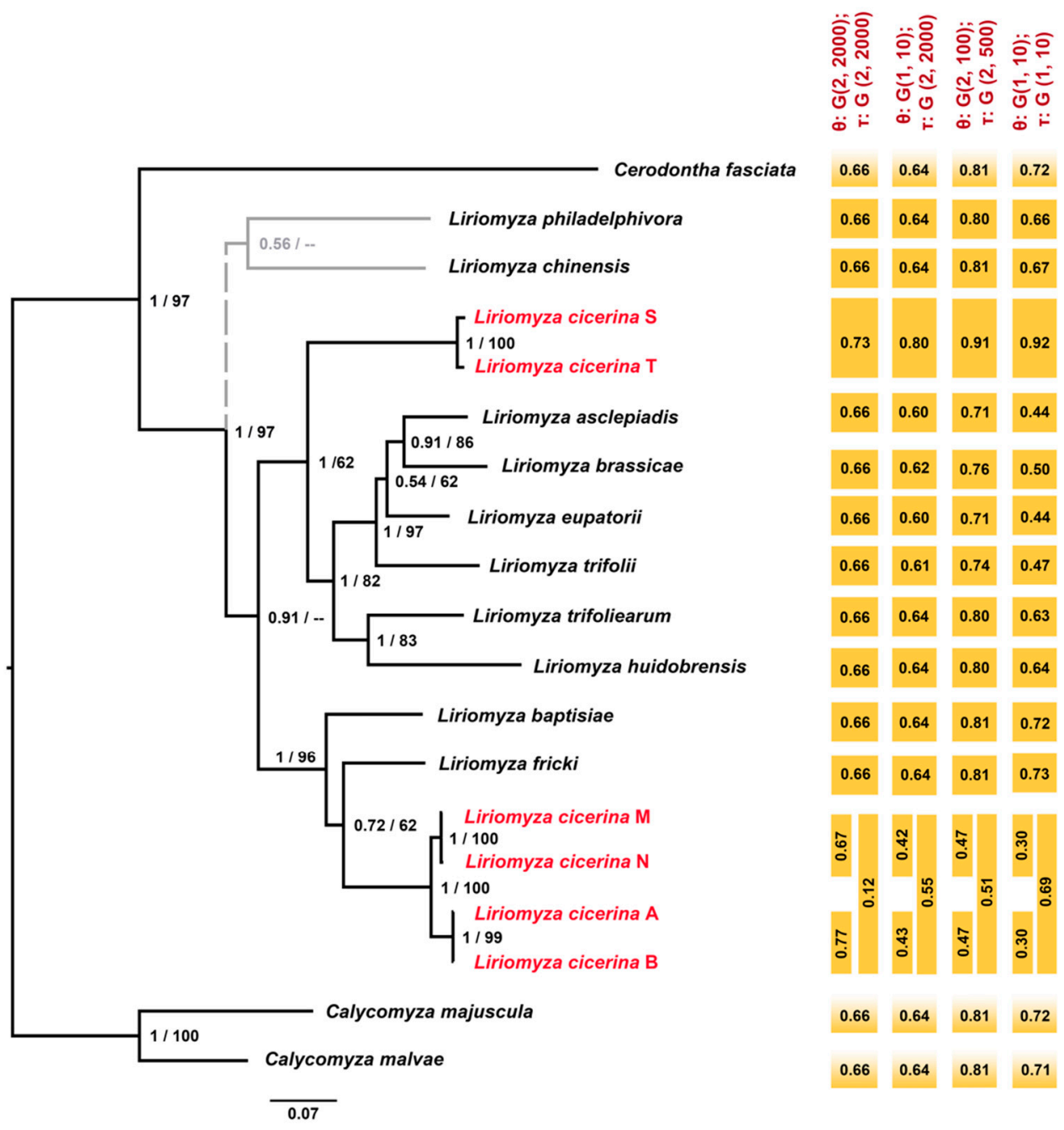

Figure 4. Tree topology obtained through BI, applying the concatenated data set of $\operatorname{cox} 1, C A D$ and $28 S$. At each node, the posterior probabilities and the bootstrap values are shown; dashes depict when the node was absent in the ML topology. In gray, the cluster (Liriomyza chinensis, Liriomyza philadelphivora) absent in the ML tree. In red, the three phylogroups hidden within L. cicerina. On the right, results of the BPP multi-locus analyses are shown, together with the respective posterior probabilities for each identified species.

Additional (up to 31) species are retrieved by a limited number of methods. The two PTP "RAxML 1-2" (with or without outgroups) analyses point for a total of 29 species, due to the distinction of 
haplotypes 1 and 2 of L. helianthi into two separate taxonomic units (light blue bars in Figure 2). Whereas, the largest number (31) of species is proposed by both PTP "MrBayes 2" (without the outgroup species) and GMYC methods, due to the split of the L. fricki haplotypes into four presumed lineages (blue bars in Figure 2) (although none of the independent clusters is sufficiently supported by PP values).

To summarize, two species (L. fricki and L. helianthi) are frequently retrieved as single taxonomic units, but alternatively also as a complex species, depending on the applied analysis. As for L. sativae, a single taxon is defined only when two haplotypes (probably belonging to mislabeled specimens) are excluded from the species delimitation analyses.

Eventually, three host-specific separate lineages are currently named as L. cicerina according to the single-locus analyses performed using the mitochondrial barcode gene (Figure 2). Instead, when these results are tested through the BPP software, the three host-specific clusters are not fully validated. On one hand, the separation of specimens sampled on faba bean leaves from those isolated from chickpea and lentil is clearly confirmed by each analysis. On the other, the putative species, corresponding to samples from C. arietinum and L. culinaris, respectively, are validated neither by some BPP analyses running the CAD data set (yellow bars in Figure 3A), nor by those performed using the $28 \mathrm{~S}$ single-locus analyses (green bars in Figure 3B).

These latter evidences, that would treat L. cicerina as a species complex, are also confirmed by the multi-locus species delimitation approaches, that assign the "faba bean" specimens to an unknown Liriomyza species. However, it is still unclear (low PP values) whether to distinguish as separate taxonomic groups the L. cicerina specimens collected on chickpea and lentil (double orange bars in Figure 4).

\section{Discussion}

Despite the high interest (and economic concern) for the pest insect as source of disturbance on cultivars of Fabaceae, in the whole Mediterranean region, studies on the population genetics of L. cicerina are essentially missing. Traditional view based on the fly interaction with its main affected host, would suggest a close relationships of $L$. cicerina with C. arietinum. However, at least one record of adult stages of this leafminer species emerging from $V$. faba has been observed in Egypt at the beginning of this century [15]; and other plants of the family Fabaceae, related to each other, are also considered hosts for the fly larvae. Levels of genetic differentiation among the L. cicerina specimens, affecting alternative host plants, are still unknown, and no systematic study has been performed to evaluate whether only one polyphagous taxon mines several plants or if more than one species is present, each one with its preferred host to feed on. On the other hand, previous studies on other congeneric taxa also imply that distinct cryptic species may be hidden within the same species-complex [40] and recommend a systematic revision to delimit dubious inter and intra-specific relationships [41]. Furthermore, within-species differentiation of Liriomyza spp., also relate to the host choice, e.g., at least one record of a L. trifolii population, apparently specialized to feed only on pepper, led to the speculation that new host affiliation may emerge from polyphagous lineages and be relevant to arise incipient (cryptic) species differentiation [40]. In addition, the genus Liriomyza is considered the Agromyzidae lineage with the largest number of host-plant families utilized and with marked tendency towards polyphagy [10].

In this study, molecular evidence attempts to define the systematic relationships among three different groups of host-specific larvae identified as L. cicerina.

Molecular analyses are particularly useful for the species identification of the genus, due to the uniformity of the morphological characters, and also because collected data can be obtained from all life stages and do not necessarily rely on the study of the reproductive apparatus of the male adults (the only diagnostic character applied with some effectiveness for species sorting). Genetic divergence observed among (cox1) haplotypes in the Tunisian population of the species collected on V. faba with respect to all other congeneric samples (including those mining the leaves of chickpea and lentil) spans 
from $\sim 11 \%$ to $17 \%$. These values are largely in the range of between-species comparisons (Table 2), with the highest similarity detected with respect to L. kenti and L. ranunculoides. Furthermore, nucleotide divergence between L. cicerina whose larvae were sampled on C. arietinum and L. culinaris is around $5 \%$; a very similar value to that $(6 \%)$ detected among the two morphocryptic and morphologically indistinguishable species L. huidobrensis and L. langei [10], or to the 7-8\% observed among the closely related L. bryoniae, L. huidobrensis/L. langei and L. strigata. Therefore, host-associated divergence in mitochondrial sequences has been detected (Figure 1), with the only exception of one haplotype belonging to the "chickpea" network cluster, that is also present in a specimen collected on lentil.

The application of the species delimitation methods, using several molecular data, returns a substantially concordant pattern of species diversity, with respect to the traditional systematics of the group. Most of the species are recovered as separate taxonomic units, with few exceptions. Among them, one method (PTP) supports the subdivision of L. helianthi into two species (although with the lack of statistical support). Two methods (PTP and GMYC) propose as many molecular species as the four phylogroups of L. fricki obtained on Figure 2. As in the case of L. cicerina, all the species delimitation approaches have split the four L. baptisiae haplotypes into two different groups $(1+2$ and $3+4)$, generally with a high statistical support (Figure 2). These results are also supported by the genetic distance comparison among the two clusters (12.77\%, Table 2), thus suggesting the presence of cryptic species so far identified as L. baptisiae. Apart from the above cases and the misidentification/mislabeling problems, probably affecting the position over the phylogenetic tree of some L. sativae and L. trifolii samples, both single- and multi-locus analyses are relatively concordant each other and lined up with traditional taxonomic subdivision of species. Phylogenetic relationships confirm the sister group L. huidobrensis/L. langei with L. bryoniae/L. strigata, and beween L. sativae and L. trifolii, as also proposed on morphological ground, i.e., the similarity of the male genitalia (especially in the shape of the distiphallus), the body color and the fine structure of the larvae's spiracles (e.g., see Groups 1 and 2 larvae in International Plant Protection Collection, 2016 [42]).

According to the genetic distances parameters, phylogenetic studies and most of the species delimitation methods herein applied, the specimens identified as L. cicerina from $V$. faba host are probably belonging to a different Liriomyza species that clusters together with L. kenti and L. ranunculoides (not with the other two L. cicerina phylogroups). However, it is not possible to establish with certainty if the specimens collected on faba bean belong to a new species of the genus; indeed, not all the species, so far described with a morphological approach, are further characterized from a molecular point of view. However, the distinction between them and the other specimens of the L. cicerina complex is fully supported by all the species delimitations approaches (i.e., either the discovery and the validation tools). The same applies for the three single-locus data sets, tested either individually and concatenated for the species delimitation, as well as for the gene tree inference (Figures 2 and 3). In this respect, only a more in-depth morphological analysis may be conclusive to establish if a new Liriomyza species should be described or if the specimens collected from $V$. faba can be assigned to an already-known taxon, so far never analyzed for molecular taxonomy and phylogeny.

Instead, the taxonomic status of the specimens collected on C. arietinum and L. culinaris is still questionable. Approaches based on different data, assumptions and algorithms are not unanimous in defining these lineages as well differentiated groups. Therefore, it is likely that incipient species may have been collected on lentil and chickpea, respectively. These two are reciprocally sister group in all the phylogenetic trees, obtained either with single- and multi-locus data sets, as well as applying both BI and ML (Figures 2-4). Moreover, one specimen collected on lentil, shows the most frequent haplotype (A), thus clustering within the sub-network of the "chickpea" phylogroup (Table 1, Figure 1). However, either the genetic distances and most of the species delimitation methods would suggest the presence of two different species (Table 2, Figures 2 and 3); other approaches would instead confirm the occurrence of a single L. cicerina taxon (Figures 3 and 4).

According to these conflicting results and following the unified species concept [17], it is possible to speculate that: (1) incipient species diversification may be occurring, but still with a certain degree 
of gene flow still active; and/or (2) the most frequent haplotype A, being the only one found on both chickpea and lentil, belong to a polyphagous and less host-restricted genetic group.

It is worth to notice, that all samples processed in this study have been collected on cultivars and therefore, it is difficult to state what is the impact of the agricultural activities on the genetic structure and pest mobility of the species. Haplotypes network analysis points for the existence of three defined sub-clades, with several singletons that appear to be associated to restricted geographic areas.

Molecular clock estimates, applying the generalized insect mitochondrial DNA estimate of 1.5-2.3\% sequence divergence rates per Myr (Million years) [33], date the separation of L. cicerina collected on faba bean from L. kenti and L. ranunculoides between 4.9 to $7.6 \mathrm{Myr}$ ago. Whereas the separation of "chickpea" and "lentil" haplotypes occurred 1.9 to 3.1 Myr ago. These latter estimates conform with those observed among the well-known cryptic species L. huidobrensis and L. langei, that diverged around $2 \mathrm{Myr}$ ago [41]. In conclusion, proposed species delimitation and population genetics studies highlight that at least two cryptic species are hidden under the taxonomic name L. cicerina, which is actually a species complex composed of closely related taxa, very similar in appearance to the point that the boundaries between them are often unclear and presently only distinguishable on molecular ground.

As a matter of fact, a preliminary morphological analysis applied to both insect pests attacking lentil and chickpea crops, suggests that the male distiphallus is with distal lobes meeting their rims to their bases, as expected in L. cicerina [2,43]; whereas that of the specimens collected on faba bean is paired and sac-shaped (as seen from the ventral side). In addition, larval stages of the specimens collected on faba bean show morphological characters (i.e., the pigmentation) that are not conclusive for taxonomic diagnosis (unpublished data).

It is worth to notice that L. huidobrensis is one of the most polyphagous species of the genus, with several records of pest activity on faba bean [6]. In this respect, we have initially tested what was the degree of genetic affinity between this species and the Liriomyza specimens collected on faba bean in Béja. Eventually, phylogenetic and genetic distance analyses both suggest that the Liriomyza samples (haplotypes P-U; Table 2, Figures 2-4) collected on faba bean do not correspond to L. huidobrensis, for four main reasons: (1) the placement within the phylogenetic trees (both single- and multi-locus analyses) in an independent position with respect to the other L. huidobrensis downloaded from public databases; (2) this latter species, conventionally clusters with L. langei commonly considered its sibling species; (3) the genetic distances between the Tunisian Liriomyza specimens collected on faba bean and L. huidobrensis (12-13\%) are within the range of interspecific comparisons; (4) none of the species delimitation analyses clusters within a single molecular taxon Liriomyza "faba bean" samples and L. huidobrensis ones (Figures 2-4).

Proposed results point towards the urge of new systematic analyses in order to evaluate if neglected morphological characters useful for species discrimination may occur. Molecular data applied for this study may be functional for barcode identification and represent a useful tool for future progress and to acquire knowledge on the evolution of such a complicated leafminer genus.

Supplementary Materials: The following are available online at http:/ /www.mdpi.com/2073-4425/9/11/554/s1, Table S1: List of Liriomyza and outgroup species included in the single-(CAD and 28S) and multi-locus analyses and applied to design primer pairs to amplify and sequence nuclear markers, Table S2: List of the 24 Liriomyza and outgroup species and haplotype labels, included in the cox1 single-locus analyses.

Author Contributions: A.C., J.M.-B.J., M.A., C.L., S.A. designed the research. C.L., A.S. and M.V. performed the experiments. A.C., C.L., S.A., M.A. contributed materials/analysis tools. A.C. and C.L. wrote the paper. M.A. and J.M.-B.J. revised the paper. All authors approved the final manuscript.

Funding: This research was supported by the University of Siena and by the ministry of Agriculture, water resources and fishery in Tunisia.

Acknowledgments: We are very grateful to two anonymous reviewers for their helpful suggestions and comments.

Conflicts of Interest: The authors declare no conflict of interest. 


\section{References}

1. Scheffer, S.J.; Winkler, I.S.; Wiegmann, B.M. Phylogenetic relationships within the leaf-mining flies (Diptera: Agromyzidae) inferred from sequence data from multiple genes. Mol. Phylogenet. Evol. 2007, 42, 756-775. [CrossRef] [PubMed]

2. Spencer, K.A. Agromyzidae (Diptera) of Economic Importance; Series Entomologica 9; Dr. W. Junk B.V.: The Hague, The Netherlands, 1973; pp. 1-418.

3. EPPO A2 List of Pests Recommended for Regulation as Quarantine Pests_Version 2017-09. Available online: https:/ / www.eppo.int/ACTIVITIES/plant_quarantine/A2_list (accessed on 28 August 2018).

4. Reitz, S.R.; Trumble, J.T. Interspecific and intraspecific differences in two Liriomyza leafminer species in California. Entomol. Exp. Appl. 2002, 102, 101-113. [CrossRef]

5. Shiao, S.F. Morphological diagnosis of six Liriomyza species (Diptera: Agromyzidae) of quarantine importance in Taiwan. Appl. Entomol. Zool. 2004, 39, 27-39. [CrossRef]

6. Weintraub, P.G.; Scheffer, S.J.; Visser, D.; Valladares, G.; Correa, A.S.; Shepard, B.M.; Rauf, A.; Murphy, S.T.; Mujica, N.; MacVean, C.; et al. The invasive Liriomyza huidobrensis (Diptera: Agromyzidae): understanding its pest status and management globally. J. Insect Sci. 2017, 17. [CrossRef] [PubMed]

7. Wang, S.Y.; Lei, Z.R.; Wang, H.H.; Dong, B.X.; Ren, B.Z. The complete mitochondrial genome of the leafminer Liriomyza trifolii (Diptera: Agromyzidae). Mol. Biol. Rep. 2011, 38, 687-692. [CrossRef] [PubMed]

8. Yang, F.; Du, Y.Z.; Wang, L.P.; Cao, J.M.; Yu, W.W. The complete mitochondrial genome of the leafminer Liriomyza sativae (Diptera: Agromyzidae): Great difference in the A+T-rich region compared to Liriomyza trifolii. Gene 2011, 485, 7-15. [CrossRef] [PubMed]

9. Yang, F.; Du, Y.Z.; Cao, J.M.; Huang, F.N. Analysis of three leafminers' complete mitochondrial genomes. Gene 2013, 529, 1-6. [CrossRef] [PubMed]

10. Scheffer, S.J.; Lewis, M.L.; Gaimari, S.D.; Reitz, S.R. Molecular survey for the invasive leafminer pest Liriomyza huidobrensis (Diptera: Agromyzidae) in California uncovers only the native pest Liriomyza langei. J. Econ. Entomol. 2014, 107, 1959-1964. [CrossRef] [PubMed]

11. Scheffer, S.J.; Wijesekara, A.; Visser, D.; Hallett, R.H. Polymerase chain reaction-restriction fragment-length polymorphism method to distinguish Liriomyza huidobrensis from L. langei (Diptera: Agromyzidae) applied to three recent leafminer invasions. J. Econ. Entomol. 2001, 94, 1177-1182. [CrossRef] [PubMed]

12. Kox, L.F.F.; Van Den Beld, H.E.; Lindhout, B.I.; De Goffau, L.J.W. Identification of economically important Liriomyza species by PCR-RFLP analysis. EPPO Bull. 2005, 35, 79-85. [CrossRef]

13. Nakamura, S.; Masuda, T.; Mochizuki, A.; Konishi, K.; Tokumaru, S.; Ueno, K.; Yamaguchi, T. Primer design for identifying economically important Liriomyza species (Diptera: Agromyzidae) by multiplex PCR. Mol. Ecol. Resour. 2013, 13, 96-102. [CrossRef] [PubMed]

14. Sooda, A.; Gunawardana, D.; Li, D.M.; Kumarasinghe, L. Multiplex real-time PCR assay for the detection of three invasive leafminer species: Liriomyza huidobrensis, L. sativae and L. trifolii (Diptera: Agromyzidae). Austral Entomol. 2017, 56, 153-159. [CrossRef]

15. El-Serwy, S.A. Studies on the leafminer; Liriomyza cicerina (Rondani) and Liriomyza bryoniae (Kaltenbach) (Diptera: Agromyzidae) and their parasitoids in faba bean in Egypt. Egypt J. Agric. Res. 2003, 81, 1581-1593.

16. Sukumaran, J.; Knowles, L.L. Multispecies coalescent delimits structure, not species. Proc. Natl. Acad. Sci. USA 2017, 114, 1607-1612. [CrossRef] [PubMed]

17. De Queiroz, K. Species concepts and species delimitation. Syst. Biol. 2007, 56, 879-886. [CrossRef] [PubMed]

18. Shutterstock. Available online: https://www.shutterstock.com/it/ (accessed on 25 July 2018).

19. Folmer, O.; Black, M.; Hoeh, W.; Lutz, R.; Vrijenhoek, R. DNA primers for amplification of mitochondrial cytochrome c oxidase subunit I from diverse metazoan invertebrates. Mol. Mar. Biol. Biotechnol. 1994, 3, 294-299. [PubMed]

20. Mesquite 3.51. Available online: https://github.com/MesquiteProject/MesquiteCore (accessed on 28 June 2018).

21. Castresana, J. Selection of conserved blocks from multiple alignments for their use in phylogenetic analysis. Mol. Biol. Evol. 2000, 17, 540-552. [CrossRef] [PubMed]

22. Clement, M.; Posada, D.; Crandall, K.A. TCS: A computer program to estimate gene genealogies. Mol. Ecol. 2000, 9, 1657-1659. [CrossRef] [PubMed]

23. Villesen, P. FaBox: An online toolbox for FASTA sequences. Mol. Ecol. Notes 2007, 7, 965-968. [CrossRef] 
24. Paradis, E.; Claude, J.; Strimmer, K. APE: Analyses of phylogenetics and evolution in R language. Bioinformatics 2004, 20, 289-290. [CrossRef] [PubMed]

25. Lanfear, R.; Frandsen, P.B.; Wright, A.M.; Senfeld, T.; Calcott, B. PartitionFinder 2: New methods for selecting partitioned models of evolution for molecular and morphological phylogenetic analyses. Mol. Biol. Evol. 2017, 34, 772-773. [CrossRef] [PubMed]

26. Stamatakis, A. RAxML version 8: A tool for phylogenetic analysis and post-analysis of large phylogenies. Bioinformatics 2014, 30, 1312-1313. [CrossRef] [PubMed]

27. Ronquist, F.; Teslenko, M.; van der Mark, P.; Ayres, D.L.; Darling, A.; Hohna, S.; Larget, B.; Liu, L.; Suchard, M.A.; Huelsenbeck, J.P. MrBayes 3.2: Efficient Bayesian phylogenetic inference and model choice across a large model space. Syst. Biol. 2012, 61, 539-542. [CrossRef] [PubMed]

28. Miller, M.A.; Schwartz, T.; Pickett, B.E.; He, S.; Klem, E.B.; Scheuermann, R.H.; Passarotti, M.; Kaufman, S.; O'Leary, M.A. A RESTful API for access to phylogenetic pools via the CIPRES Science Gateway. Evol. Bioinform. Online 2015, 11, 43-48. [CrossRef] [PubMed]

29. Puillandre, N.; Lambert, A.; Brouillet, S.; Achaz, G. ABGD, Automatic Barcode Gap Discovery for primary species delimitation. Mol. Ecol. 2012, 21, 1864-1877. [CrossRef] [PubMed]

30. Species Identifier. Available online: https://github.com/gaurav/taxondna/releases/tag/1.8 (accessed on 23 June 2018).

31. Zhang, J.J.; Kapli, P.; Pavlidis, P.; Stamatakis, A. A general species delimitation method with applications to phylogenetic placements. Bioinformatics 2013, 29, 2869-2876. [CrossRef] [PubMed]

32. Bouckaert, R.; Heled, J.; Kuhnert, D.; Vaughan, T.; Wu, C.H.; Xie, D.; Suchard, M.A.; Rambaut, A.; Drummond, A.J. BEAST 2: A software platform for Bayesian evolutionary analysis. PLoS Comput. Biol. 2014, 10. [CrossRef] [PubMed]

33. Brower, A.V.Z. Rapid morphological radiation and convergence among races of the butterfly Heliconius erato inferred from patterns of mitochondrial-DNA evolution. Proc. Natl. Acad. Sci. USA 1994, 91, 6491-6495. [CrossRef] [PubMed]

34. Rambaut, A.; Drummond, A.J.; Xie, D.; Baele, G.; Suchard, M.A. Posterior summarization in Bayesian phylogenetics using Tracer 1.7. Syst. Biol. 2018, 67, 901-904. [CrossRef] [PubMed]

35. FigTree v1.4.3. Available online: http://tree.bio.ed.ac.uk/software/figtree/ (accessed on 28 August 2018).

36. Fujisawa, T.; Barraclough, T.G. Delimiting species using single-locus data and the Generalized Mixed Yule Coalescent approach: A revised method and evaluation on simulated data sets. Syst. Biol. 2013, 62, 707-724. [CrossRef] [PubMed]

37. R Core Team. R: A Language and Environment for Statistical Computing; R Foundation for Statistical Computing: Vienna, Austria, 2014. Available online: http:/ /www.R-project.org/ (accessed on 2 July 2018).

38. Ezard, T.; Fujisawa, T.; Barraclough, T. Splits: Species' Limits by Threshold Statistics. R Package Version 1.0-19. 2014. Available online: http:/ / R-Forge.R-project.org/projects/splits / (accessed on 23 May 2018).

39. Yang, Z.; Rannala, B. Unguided species delimitation using DNA sequence data from multiple loci. Mol. Biol. Evol. 2014, 31, 3125-3135. [CrossRef] [PubMed]

40. Scheffer, S.J.; Lewis, M.L. Mitochondrial phylogeography of vegetable pest Liriomyza sativae (Diptera: Agromyzidae): Divergent clades and invasive Populations. Ann. Entomol. Soc. Am. 2005, 98, 181-186. [CrossRef]

41. Scheffer, S.J. Molecular evidence of cryptic species within the Liriomyza huidobrensis (Diptera: Agromyzidae). J. Econ. Entomol. 2000, 93, 1146-1151. [CrossRef] [PubMed]

42. International Plant Protection Convention (ISPM 27-Annex 16). DP 16: Genus Liriomyza. Available online: https:/ / www.ippc.int/static/media/files / publication/en/2017/01/DP_16_2016_En_2017-01-30. pdf (accessed on 28 August 2018).

43. Maharjan, R.; Oh, H.W.; Jung, C. Morphological and genetic characteristics of Liriomyza huidobrensis (Blanchard) (Diptera: Agromyzidae) infesting potato crops in Korea. J. Asia-Pac. Entomol. 2014, 17, 281-286. [CrossRef]

(C) 2018 by the authors. Licensee MDPI, Basel, Switzerland. This article is an open access article distributed under the terms and conditions of the Creative Commons Attribution (CC BY) license (http:/ / creativecommons.org/licenses/by/4.0/). 